\title{
PROCESSO DE SOCIALIZAÇÃO NA FORMAÇÃO IDENTITÁRIA DO ESTUDANTE DE MEDICINA
}

\author{
SOCIALIZATION PROCESS IN THE IDENTITY DEVELOPMENT \\ OF THE MEDICINE STUDENT
}

\author{
Clarisse Daminelli Borges Machado iD) ${ }_{(0000-0002-3385-8455)^{1}}$, Andrea Soares Wuo iD) ${ }_{(0000-0003-2110-7184)^{1}}$ \\ ${ }^{1}$ Fundação Universidade Regional de Blumenau, Centro de Ciências da Educação, Artes e Letras, \\ Blumenau, Programa de Pós-Graduação em Educação, Santa Catarina, Brasil. \\ $<$ clarissedbm@gmail.com>
}

Resumo Este artigo teve por objetivo evidenciar e analisar as mudanças relativas às expectativas do tornar-se médico ao longo da graduação em medicina. Fizeram parte da pesquisa, realizada entre abril e junho de 2018, estudantes de medicina matriculados na primeira, quinta, oitava e décima segunda fases de uma instituição pública de Ensino Superior de Santa Catarina. Após aplicação de questionário, foram analisadas 145 respostas à seguinte pergunta: Por que você escolheu cursar medicina? Por meio de análise de conteúdo, evidenciou a presença crescente, no decorrer do curso, por aquilo que denominamos de 'retorno financeiro' e, de maneira inversa, o decrescente interesse por 'ajudar ao próximo'. Os resultados, analisados com base em teorias que abordam os processos de socialização e de formação identitária mostraram que, apesar de inseridos em realidades socioculturais distintas, os indivíduos se encontram envoltos por ritos e estereótipos comuns, socialmente convencionados por padrões social e historicamente construídos pelo processo de constituição da identidade médica.

Palavras-chave educação médica; socialização; formação identitária; identidade profissional.
Abstract The article had the goal of evidencing and analyzing the changes regarding the expectations involving becoming a doctor throughout Medicine undergraduate studies. Between April and June 2018, Medicine students enrolled in the first, fifth, eighth and tenth stages of a public higher education institution in the state of Santa Catarina, Brazil, took part in the study. After a questionnaire was applied, we analyzed 145 answers regarding the following question: Why did you choose to take Medicine course? Through content analysis, the data analysis evidenced a growing presence, throughout the course, of what we call 'financial return,' and, inversely, a decreasing interest in 'helping others.' The results, which were analyzed based on theories that approach the socialization and identity development processes, revealed that, in spite the fact that they are inserted into different sociocultural realities, the individuals find themselves involved with rituals and common stereotypes that are socially arbitrated by patterns that were socially and historically developed by the process of constitution of the medical identity.

Keywords medical training; socialization; identity development; professional identity. 


\section{Introdução}

A entrada do estudante no curso de medicina proporciona sua inserção em um novo grupo de convívio e a iniciação a uma nova classe profissional. O processo de formação identitária, sustentado pelos contextos histórico e sociofamiliar, bem como pela trajetória social construída ao longo do curso, parece resultar nas características próprias deste sujeito em formação.

O indivíduo, como sujeito de sua própria história, é resultado das ações sociais das quais participa, sendo, simultaneamente, determinado e determinante. Ao pertencer a um grupo, o indivíduo tem sua identidade social definida, e o ato de manter-se em movimento dentro deste grupo confere ao sujeito a possibilidade de desenvolver sua individualidade.

A função do grupo é definir papéis e, consequentemente, a identidade social dos indivíduos; é garantir a sua produtividade social. O grupo coeso, estruturado, é um grupo ideal, acabado, como se os indivíduos envolvidos estacionassem e os processos de interação pudessem se tornar circulares. (Lane, 2012, p.79)

A trajetória acadêmica de um estudante de medicina costuma ser linear e, na maioria das vezes, muito semelhante à de seus pares. São seis anos de curso, geralmente precedidos por outros anos de estudos preparatórios para o vestibular, justificados por uma disputa gerada pela desproporção entre o número de vagas e estudantes inscritos nestas provas (Santos, 2012). Imersos na busca incessante pela aprovação em um curso com grande disputa, os estudantes identificam a necessidade de lidar com a concorrência entre os colegas, e levam boa parte desta vivência para a graduação.

O convívio diário e o ritmo de avaliações impostas pelo curso parecem fazer aflorar a competitividade já experimentada anteriormente por esses estudantes. Além da aprovação nas disciplinas, há a busca, especialmente no final da graduação, para a aprovação na residência médica. Tornar-se especialista, atualmente, parece ser mais do que opção profissional ou a sequência natural de aprimoração de conhecimentos, perpassa por um contexto de reconhecimento dentro da classe médica e pela sociedade de modo geral (Rios, 2010). Sob este aspecto, ganha corpo a tendência de uma educação médica tecnicista, com ênfase nas especialidades e no individualismo.

Orientados pela pergunta de pesquisa 'Como se dá a formação identitária profissional do estudante de medicina?', temos como objetivo compreender o processo de formação identitária, por meio de socialização acadêmica de estudantes de medicina da Fundação Universidade Regional de Blumenau (FURB). Dessa forma, será possível identificar as mudanças nas perspectivas do tornar-se médico durante sua trajetória na graduação. 


\section{O processo de socialização}

A sociologia investiga, desde o seu surgimento como ciência no século XIX, as relações entre indivíduo e sociedade. Émile Durkheim (1858-1917), fundador da escola francesa de sociologia, já explicava a socialização por meio do fato social:

É fato social toda maneira de agir, fixa ou não, suscetível de exercer sobre o indivíduo uma coerção exterior; ou, ainda, que é geral ao conjunto de uma sociedade dada e, ao mesmo tempo, possui existência própria, independente das manifestações individuais que possa ter (Durkheim, 1972, p.11).

Contemporaneamente, o conceito de socialização, identificado como uma transmissão de valores, pautado pela coerção e pelo espírito de disciplina, apenas complementado por um vínculo com determinados grupos sociais, não se mostra suficiente como fundamentação das relações em sociedade (Dubar, 2005). As contribuições de Durkheim (1972) para o aprofundamento e a compreensão do processo de socialização são inúmeras, apesar de se mostrarem, atualmente, ultrapassadas.

Mesmo defendendo o espírito coercitivo e a transmissão de valores, regras e normas através de seguidas gerações, Durkheim (1972) mostra-se atento ao processo de surgimento de autonomia do indivíduo. Aos laços que unem os indivíduos à sociedade, Durkheim (1972) denomina de solidariedade e, com base nessa noção, caracteriza duas formas de organização social: sociedades tradicionais, caracterizadas por relações de solidariedade mecânica, e modernas, denominadas orgânicas.

Ao caracterizar as relações sociais como mecânicas ou orgânicas, distingue as duas formas, basicamente, pela imitação externa da primeira, em que há um baixo grau de consciência individual, uma vez que predomina uma consciência coletiva que controla a sociedade. E, de maneira oposta, a cooperação e complementaridade da segunda, sendo esta última característica das sociedades atuais, capitalistas (Dubar, 2005). Ao classificar como cooperativa as relações entre os sujeitos na solidariedade orgânica, Durkheim (1972) evidencia esse processo de individualização.

Ao refutar o consenso social obtido por meio da coerção, Max Weber (1864-1920) apresenta-se como o teórico da subjetividade. Segundo Costa (2000), Weber cunha o termo 'ação social' ao construir o pensamento sociológico por meio da subjetividade das ações. Para o referido autor, "Seu objeto de investigação é a ação social, a conduta humana dotada de sentido, isto

é, de uma justificativa subjetivamente elaborada. Assim, o homem passou a 
ter, enquanto indivíduo, na teoria weberiana, significado e especificidade" (Costa, 2000, p.72).

Em sua obra intitulada Conceitos básicos de sociologia, Weber (2002) apresenta duas formas de comportamento de um indivíduo em relação ao de outros: a socialização comunitária, ou o processo de entrada na comunidade, e a socialização societária, ou o processo de entrada na sociedade. O ponto de diferenciação entre ambas encontra-se no sentimento de pertencimento comum e de ação emocional da primeira em contraponto ao caráter racional e legalista da segunda.

Mesmo com a clara cisão teórica entre os dois modelos de socialização, Weber (2002) não concebe esta mesma separação na prática. O autor considera as duas formas de relações sociais apresentadas como tipos ideais, apenas produtos de diferentes pontos de vista, afirma que "a grande maioria das relações sociais tem em parte o caráter de uma socialização comunitária e em parte o de uma socialização societária." (apud Dubar, 2005, p.111). Assim, segundo Weber (2002), toda a relação societária que se estabelece por muito tempo acaba por criar vínculos emocionais e, portanto, passa a apresentar características da socialização comunitária (Dubar, 2005).

Ainda, de acordo com a teoria weberiana, as sociedades modernas são fundamentadas por relações sociais de cunho societário, evidenciadas pela racionalização das relações. Max Weber (2002) atribui este processo de racionalização à fragmentação do espaço social "em áreas jurisdicionais distintas, fixadas oficialmente e determinadas por regras específicas, ou seja, por leis ou regulamentos administrados" (apud Dubar, 2005, p. 112). Evidência deste processo é a burocratização das instituições, com estruturas compartimentadas, divididas hierarquicamente e superespecializadas. Esta configuração institucional é fomentadora da crescente "autonomização dos campos de atividade social", em que os interesses particulares dos indivíduos envolvidos acabam por moldar as relações sociais, em detrimento do coletivo (Dubar, 2005, p. 99).

Assim como Weber (2002), George Herbert Mead (1934) define socialização como a construção de um indivíduo social em sua interação com outros indivíduos. Considera que "o fato primordial é o ato social que implica a interação de diferentes organismos, ou seja, a adaptação recíproca de suas condutas na elaboração do processo social" (apud Dubar, 2005, p. 115). Mead é o responsável pela elaboração do conceito de self, em que teoriza que a individualidade do sujeito só se torna possível "ao refletir o indivíduo como sujeito e objeto ao mesmo tempo" (Sant'ana, 2007, p. 132).

Segundo Dubar (2005), Mead organiza o processo de socialização em três momentos. A primeira etapa da socialização ocorre com a criança assumindo diferentes papéis, incorporados daqueles com os quais convive, e que Mead denomina de seus outros significativos. O papel incorporado seria, justamente, um conjunto de gestos e comunicações, aqui denominados de símbolos, que 
identificam uma personagem socialmente reconhecida e de fácil identificação. Este processo oferece à criança a possibilidade de "assumir atitudes, inverter papéis, alterar seus gestos e depois sua voz" (Mead apud Dubar, 2005, p.117), experimenta, assim, reações que ela provoca em outros e que outros provocam nela.

A etapa seguinte consiste na inserção da criança em um ambiente com normas estabelecidas, em que ela deverá conviver com outras crianças, interpretar diferentes papéis, sob as mesmas regras. Segundo Mead, ela deverá "assumir a atitude de todo indivíduo que participa do jogo" e que "a atitude de uma provoca a atitude apropriada da outra" (apud Dubar, 2005, p. 117). Por meio deste processo, afirma Mead, a criança percebe que o outro não é mais uma personagem isolada, representante de um papel apenas, mas a "organização das atitudes das pessoas que estão engajadas no mesmo processo social". A esta organização Mead denomina o outro generalizado e, é por meio do reconhecimento deste outro que a construção do si-mesmo se faz possível (Dubar, 2005, p. 119).

A terceira e última etapa da socialização, segundo Mead apud Dubar (2005), caracteriza-se pelo reconhecimento da criança como membro daquela organização de "outros generalizados", as quais se identificou previamente. Dubar (2005) afirma que este pertencimento a um determinado grupo, pelo reconhecimento do si-mesmo, indica que a criança não atuou apenas como um receptor, como um sujeito que interiorizou passivamente os valores do grupo, mas sim, como uma personagem que tenha representatividade e importância no grupo.

Deste processo de reconhecimento do si-mesmo, desdobram-se dois componentes do self, por Mead denominados de 'Mim' e 'Eu'. O 'Mim' é a face do self que torna a criança pertencente a determinado grupo, ou seja, é a parte do ser social que interiorizou as normas e valores necessários para se tornar parte de um coletivo. Já o 'Eu' caracteriza-se por ser a face que se mostra individualizada, que permite ao indivíduo assumir um papel próprio no grupo, exteriorizando valores particulares e, desta forma, imprimindo sua autonomia (Dubar, 2005; Sant'ana, 2007).

Segundo Dubar (2005, p.120), Berger e Luckmann (1976) "retomam e prolongam as análises de Mead, introduzindo uma distinção interessante entre socialização primária e secundária". O processo de socialização é por Berger e Luckmann (1976, p.175) definido como "a ampla e consistente introdução do indivíduo no mundo objetivo de uma sociedade ou de um setor dela." O processo de socialização ocorre por meio de relações de exteriorização, objetivação e de interiorização que o sujeito mantém, de forma dialética, com o mundo que o cerca.

A interiorização, ponto inicial deste processo, é caracterizada como a apreensão, dotada de sentido, de um evento objetivo. Ou seja, o indivíduo, 
por meio da interiorização, torna-se capaz de transformar em subjetividade própria um processo de subjetivação de outrem. Este processo permite que os sujeitos que convivem em uma mesma sociedade se reconheçam nas ações do outro e que, consequentemente, apreendam aquilo que lhes é externo, estranho. É neste engendramento de trocas e apreensões em que o primeiro ponto da socialização se firma (Berger e Luckmann, 1976).

A socialização primária, segundo Berger e Luckmann (1976), é o processo responsável pela inserção do indivíduo na sociedade. É aquela que se dá no meio familiar, realizada por pessoas próximas que, ao experimentarem seus próprios cotidianos, transmitem-nos à criança, numa transferência direta de valores e conceitos. É, portanto, uma relação mediada por emoções e afetos, fazendo desta base biográfica familiar de socialização o seu valor mais importante.

A criança, ao desenvolver-se socialmente em um determinado espaço de socialização, concebe aquele ambiente como sendo o mundo real que a cerca. É possível afirmar, portanto, que diferentes espaços de socialização, sejam eles diferenciados por classes sociais sejam ambientes familiares distintos, produzam indivíduos com perspectivas diferentes acerca da mesma realidade em que estão inseridos.

Diante da única realidade ao indivíduo apresentada neste processo de socialização, não parece haver possibilidade de escolhas na socialização primária (Berger e Luckmann, 1976). A identificação do Eu será moldada diante daquilo que a família oferecer e, por não apresentar alternativas, esta socialização tende a se fixar mais fortemente na constituição identitária do indivíduo do que qualquer outra forma de socialização secundária.

A esta segunda forma de socialização Berger e Luckmann (1976) descrevem como proveniente da consolidação da divisão do trabalho, da distribuição do conhecimento e do processo de institucionalização. Não parece possível conceber uma sociedade, atualmente, que não esteja inserida no processo econômico capitalista, evidenciada pela luta de classes e sustentada pela divisão do trabalho. Da mesma forma, não é possível afirmar que, qualquer indivíduo que se encontre inserido nesta realidade, permaneça restrito à socialização primária familiar.

Ao processo de inserção em outras realidades sociais, mediada por sujeitos com socializações distintas, chamaremos de socialização secundária. Às diferentes realidades sociais experimentadas neste processo, Berger e Luckmann (1976) denominam de submundos institucionais. São caracterizados como espaços de legitimação da distribuição social do conhecimento, organizados em instituições que fortalecem a divisão do trabalho, e dão origem às especificidades das classes profissionais.

Goffman (2001) apresenta o conceito de instituições, ou estabelecimentos sociais, como ambientes em que ocorrem atividades de determinados ti- 
pos. Estas atividades variam entre distrações, sem qualquer outra implicação maior, e a obtenção de determinado status social, em que o pertencimento a determinada instituição distingue o sujeito de outros não pertencentes. Às instituições que proporcionam ao sujeito o status, é evidente a característica de 'fechamento', já que "toda instituição conquista parte do tempo e do interesse de seus participantes e lhes dá algo de um mundo" (Goffman, 2001 , p. 16). Este processo de barreira, decorrente do 'fechamento', aparece evidenciado no distanciamento das relações sociais entre os internos às instituições e o restante da sociedade.

O indivíduo não substitui, porém, sua consciência do 'Eu social' primário pelas novas interiorizações que faz ao longo das socializações secundárias. O sujeito constrói-se mediante um misto de novos e velhos conceitos e valores, desliga-se, cada vez mais, de suas particularidades cotidianas para elevar-se às compreensões de um coletivo social.

\section{0 processo de formação identitária}

O termo identidade recebe, frente à concepção utilizada, seja ela sociológica, antropológica seja psicológica, diferentes interpretações. Neste trabalho, abordaremos a identidade dos sujeitos como um constructo diário, em constante transformação. O sociólogo Claude Dubar (2005), assim como o psicólogo social Antônio da Costa Ciampa (1998), concebem a identidade fundamentada na perspectiva de um processo de formação identitária.

A formação do sujeito se dá de forma continuada, num fluxo ininterrupto, na dialética sujeito e sociedade. Para além da cotidianidade social, embasada pelo senso comum, surge a individualização do homem, ser único e irrepetível, formado, concomitantemente, por particularidades e generalidades. Para Heller (1992, p. 20) "a dinâmica básica da particularidade individual humana é a satisfação das necessidades do 'EU'”. Em contraponto, a porção humano-genérico desenvolve-se com base nas relações sociais, imbricadas em um contexto sócio-histórico, promovendo ações com significados coletivos, em função de um 'nós'. Da união de particularidade e generalidade surge, então, a individualidade unitária, agente possibilitador de um descolamento, uma ascensão do indivíduo da cotidianidade em direção ao livre arbítrio e ao pensamento autônomo (Heller, 1992).

O ser humano, enquanto indivíduo imerso na cotidianidade, toma posse de características que a constituem, como a espontaneidade, o pragmatismo, o juízo provisório e a mimese (Heller, 1992). Valer-se destas características torna a vivência cotidiana mais prática, mais inteligível e menos racional. A mimese, por exemplo, é facilitadora das atividades laborais e sociais; o sujeito espelha-se nos seus semelhantes, contemporâneos ou não, na realização de suas ações e comportamentos. 
O mundo da vida cotidiana não somente é tomado como uma realidade certa pelos membros ordinários da sociedade na conduta subjetivamente dotada de sentido que imprimem a suas vidas, mas é um mundo que se origina no pensamento e na ação dos homens comuns, sendo afirmado como real por eles. (Berger e Luckmann, 1976, p. 36)

Apesar de facilitadores, tais conceitos não devem ser cristalizados como verdades absolutas e sim permitir ao indivíduo que se movimente, que desenvolva conceitos próprios. Segundo Heller (1992), quando o ser humano impõe a sua essência ao cotidiano, ele transforma a sua experiência de cotidianidade e gera uma condução representativa da vida. Quando contrário, há uma alienação da vida diante da cristalização da cotidianidade.

Manter-se na cotidianidade, seguindo determinados padrões de linguagem ou de atitudes, representa a reprodução de uma ideologia social já cristalizada. É François Flahault (1978) apud Lane (2012) quem descreve a maneira com que, por meio da mimese, o sujeito perpetua as representações sociais presentes em seu meio de convivência. Para tanto, desenvolve o conceito de Espaço de Realização do Sujeito (ERS), caracterizado como o movimento em que o sujeito, ao constituir-se, devolve à sociedade aquilo que o constituiu. Ao atuar como uma espécie de regulador social, através do imaginário e do simbólico, o ERS fundamenta-se como o espaço em que os indivíduos têm constituídas suas identidades sociais Lane (2012) afirma que os espaços de construção social estão intimamente ligados às instituições sociais, sendo estas responsáveis pela mediação ideológica na construção e atribuição de papéis e representações sociais dos indivíduos. A institucionalização surge da tipificação de ações habituais, ditas cotidianas, por determinados tipos de atores. Indivíduos, caracterizados como pertencentes a determinada instituição, assumem papéis que possibilitem, aos demais sujeitos, reconhecê-los como representantes da instituição a qual pertencem.

Todos os processos de formação de hábitos antecedem a institucionalização dos membros, esta ocorrendo sempre quando as atividades tomadas hábitos se amoldam em tipos de ações que são executadas por determinados indivíduos. Assim, a instituição pressupõe que, por exemplo, o dirigente e o funcionário ajam de acordo com as normas estabelecidas, e assim por diante. É importante notar que essas tipificações são elaboradas no curso da história da instituição, daí só se poder compreender qualquer instituição se aprendermos o processo histórico no qual ela foi produzida. (Lane, 2012, p. 83)

Ciampa (1998) constrói o conceito de identidade como sendo um processo humano, social e histórico. Para o autor, a identidade é uma construção diária, modificada pelas relações sociais que o indivíduo mantém enquanto é exposto 
a outros indivíduos e valores, sendo o indivíduo isolado, uma abstração. “A identidade se concretiza na atividade social. O mundo, criação humana, é o lugar do homem. Uma identidade que não se realiza na relação com o próximo é fictícia, é abstrata, é falsa" (Ciampa, 1998, p. 86).

À identidade em contínuo processo de transformação, Ciampa (1998) denomina identidade-metamorfose, caracterizada por mudanças possibilitadas pelas vivências sociais as quais se submete o indivíduo. Uma identidademetamorfose apenas pode ser assim definida quando permite ao sujeito algum grau de elevação em referência à identidade anteriormente apresentada, quando há um caminho, conforme termo empregado por Heller (1992), em direção à individualidade unitária.

Como construção histórica, a cotidianidade pode ser, por meio das diferentes identidades, alterada em um sentido emancipatório, possibilita o surgimento da individualidade unitária proposta por Heller (1992). De forma oposta, em condições as quais o sujeito opte por se manter fiel aos conceitos cristalizados pelo cotidiano, se diz então da manutenção da identidade, aquilo denominado por Ciampa (1998) de mesmice imposta. A mesmidade, oposta à metamorfose, apresenta-se ao sujeito como uma das possibilidades da cotidianidade e implica uma forma de alienação.

O indivíduo que se mantém reprodutor dos juízos provisórios do cotidiano, incapaz de experimentar de forma questionadora as contradições que permeiam o meio social ao qual pertence, permanece alienado. O ser alienado é sempre alienado em relação a alguma parte de um complexo sistema de significados e ações, e pode se encontrar nesta posição de forma consciente ou inconsciente (Lane, 2012). Quando tomado pelas facilidades propostas pela cotidianidade cristalizada, reproduz o que se apresenta como verdade, mostra-se inconsciente, porém há algum grau de consciência quando a opção por seguir preceitos cotidianos implica a manutenção de poderes, econômicos ou sociais.

À identidade, que se apresenta como resultado da transformação da identidade pressuposta de origem, e se desvela nas relações sociais do sujeito, Ciampa (1998) denomina de identidade-reposta, mantendo uma clara relação com a socialização secundária. Esta tem a característica de ser oferecida e, portanto, incorporada pelo sujeito de forma previamente definida.

Claude Dubar (2005) apresenta a definição de identidade embasada pelos conceitos de Weber (2002) de identificação comunitária e societária e por meio dos desdobramentos do self de Mead (1934). Para o autor, a identidade social do sujeito está diretamente ligada a diferentes formas de pertencimento, sendo, no início dos estudos sobre identidade (1960), a socioprofissional a mais amplamente estudada pela sociologia francesa.

São muitos os pertencimentos do sujeito que pesam sobre comportamentos e opiniões. Classes, gêneros, origem cultural e crenças religiosas são exemplos 
de pertencimentos distintos que moldam, de forma subjetiva, a identidade social. Dubar (2009) afirma que, nas sociedades contemporâneas, devido às diversidades das características individuais, faz-se necessário conhecer o sujeito como um todo, analisar todas as suas formas de pertencimento.

Em uma abordagem sociológica, a noção de identidade não se explica com base em uma perspectiva macrossocial (noções de grupo ou classe), tampouco mediante uma perspectiva microssocial (noções de papel). A identidade seria, portanto, “o resultado a um só tempo estável e provisório, individual e coletivo, subjetivo e objetivo, biográfico e estrutural, dos diversos processos de socialização que, conjuntamente, constroem os indivíduos e definem as instituições" (Dubar, 2005, p. 136).

A formação identitária se dá, para Dubar (2005), por meio de uma mistura heterogênea de identidades. Inicialmente àquela que denomina de 'identidade de atribuição', que identifica o sujeito segundo a visão do outro e, de forma complementar, a 'identidade de pertencimento', identidade do sujeito forjada por ele mesmo. Enquanto as primeiras, embora constitutivas da identidade, possam ser rejeitadas pelo sujeito, as identidades de pertencimento são incorporadas ao longo das trajetórias sociais, perfazendo um caminho em direção àquilo que o sujeito compreende como 'o que ele é' (Dubar, 2005).

Desta forma, as identidades sociais são formadas pelo arranjo daquilo que imputam ao sujeito e daquilo que ele acredita ser. Este fenômeno pode ocorrer de forma que o sujeito se adeque à identidade do outro, direciona o seu "eu" para uma conformidade com a identidade de atribuição ou, de forma contrária, persista na identidade de pertencimento. Para Dubar (2005), os sujeitos tendem a optar por uma 'negociação identitária', uma forma equilibrada entre identidade de atribuição, originada em um processo relacional, e a identidade de pertencimento, de constituição biográfica.

Desta 'negociação identitária', é a parcela biográfica que, por meio das escolhas realizadas pelo sujeito implicará projeções objetivas para o futuro. Surge daí, a construção de uma identidade profissional, inicialmente idealizada e elaborada, gradualmente, ao longo da vida escolar do sujeito. Construída a parcela pessoal da identidade profissional, cabe ao sujeito relacionar-se com o grupo ao qual pretende pertencer. Tem início um "processo relacional de investimento de si [...], um investimento essencial em relações duradouras que colocam em questão o reconhecimento recíproco dos parceiros" (Dubar, 2005, p. 151).

É o que pode ser encontrado na identificação social de determinadas profissões. Ao ser identificado pelo outro, por exemplo, como médico ou estudante de medicina, o indivíduo já recebe uma carga de conceitos, ou de representações, historicamente construídos, que o definem enquanto médico. Há uma construção histórica da figura do médico que lhe é imputada como 
identidade profissional, desdobrando-se em impressões e expectativas que não estão ligadas a um sujeito, especificamente, mas a uma identidade de classe.

Daí a expectativa generalizada de que alguém deve agir de acordo com o que é e, consequentemente, ser tratado como tal. De certa forma, reatualizamos através de rituais sociais uma identidade pressuposta que assim é reposta como algo já dado, retirando em consequência o seu caráter de historicidade, aproximando-a mais da noção de um mito que prescreve as condutas corretas, reproduzindo o social. (Ciampa, 2012, p. 66)

Acerca da identidade profissional do médico, Hughes (1958) apresenta uma cisão de classes, de uma maneira simbólica, daquilo que ele chama de sagrado e profano. Caracterizando determinadas profissões e seus representantes está o sagrado, enquanto o profano designa os demais indivíduos. Afirma que esta não é apenas uma forma de descrever determinada classe de trabalhadores, mas sim a implicação de um juízo de valores e de prestígio. $\mathrm{O}$ autor fundamenta tal concepção na ideia de que determinadas profissões alcançaram, com o passar do tempo, status de sagrado. Os médicos, por poder investido pelos profanos, são exemplos de profissionais sagrados.

Ainda, segundo Hughes (1958), este poder conferido a representantes de determinadas profissões emana do caráter íntimo e pessoal da relação entre sagrados e profanos. Como exemplo, Hughes (1958) cita a relação de confidencialidade entre médico e paciente, padre e comunidade. Segundo o autor, para que esta relação seja perpetuada, faz-se imperativo a existência das instituições, "destinadas a proteger o diploma e a conservar o mandato de seus membros" (Hughes, 1958, p. 82).

Becker (1992), em estudo com graduandos de medicina norte-americanos, na década de 1960, buscou compreender as características comuns entre os indivíduos que compunham este grupo, assim como suas trajetórias acadêmicas e pessoais. Ao observar os alunos das fases iniciais, relatou:

Eles vestirão branco, a cor símbolo da medicina moderna. Pelo resto de suas vidas passarão algumas boas horas diárias entre pessoas que vestem uniformes, mais frequentemente branco, o que mostra o local a que cada qual pertence nesta complicada divisão de trabalho e sistema de ranking do mundo médico, ao qual o topo está destinado ao estudante de medicina (Becker, 1992, p. 4, tradução nossa).

Em dois anos de estudo etnográfico, Becker (1992) notou mudanças no comportamento destes alunos. Muitas, em relação ao tornar-se médico, evidenciaram uma realidade acadêmica sem conexão com o ideal médico previamente projetado pelos estudantes. O autor descreve a entrada no mundo médico: 
Na nossa sociedade, entre as coisas mais desejadas e o status mais admirado, está o de se tornar um membro de uma profissão. [...] No treinamento para a medicina, muita ênfase é dada para a aprendizagem das ciências básicas e o seu emprego no diagnóstico e tratamento das doenças. Mas ciência e conhecimento não fazem um médico; ele deve ser também iniciado no status da medicina; para ser aceito, ele deve ter aprendido a fazer o papel do médico no drama da medicina. (Becker, 1992 , p. 4, tradução nossa)

O processo de formação da identidade dos estudantes de medicina, objeto desta pesquisa, parece receber, então, ao ser previamente definido pela identidade reposta e pelo conceito a ele atrelado pela representação social, uma métrica. Padrões, normas, ritmos e organizações as quais o estudante deve, conforme o que a sociedade espera, se adequar e cumprir. No âmbito da graduação, este "aprendizado indireto, no qual atitudes, valores, padrões de comportamento são adquiridos pelo estudante, como subproduto do contato com os instrutores e pares" (Lampert, 2009, p. 35) mescla-se e, mesmo, se sobressai aos conhecimentos e habilidades técnicas da profissão.

A identidade do estudante, em contínua transformação, apresenta-se como o produto de suas interações: de uma identidade familiar, construída pelo meio social em que cresceu, transforma-se por meio das relações que estabelece ao longo da vida acadêmica. São estas relações, permeadas pela reflexividade dos sujeitos envolvidos, que possibilitarão a metamorfose identitária do estudante.

\section{Metodologia}

Esta pesquisa ${ }^{1}$ foi realizada no período de abril a junho do ano de 2018, por meio de aplicação de questionários para estudantes de medicina matriculados no primeiro, no quinto, no oitavo e no décimo segundo semestres da Fundação Universidade Regional de Blumenau (FURB). O questionário, que segue o modelo aplicado pelo Exame Nacional de Desempenho do Estudante (Enade) (Brasil, 2016), foi composto por dois blocos. O primeiro, denominamos de bloco socioeconômico, com 16 perguntas fechadas. O segundo bloco refere-se ao perfil do ingresso, com quatro perguntas, sendo três fechadas e relacionadas, respectivamente, à frequência prévia a outros cursos de graduação, às pessoas que influenciaram a escolha do curso, ao período de tempo entre o ensino médio e o ingresso no curso de medicina. Por fim, tem-se a pergunta aberta: Por que você escolheu cursar medicina? A aplicação do questionário visou à obtenção de dados que possibilitassem uma análise do perfil socioeconômico e de ingresso dos estudantes e sua motivação inicial para a escolha do curso. Os questionários foram aplicados em sala de aula, pela pesquisadora, em horário cedido pelo professor, conforme agendamen- 
to prévio. Responderam ao questionário, de forma espontânea, todos os 145 estudantes que compunham as quatro turmas citadas.

Estes semestres foram escolhidos por apresentarem, de forma temporal, o início, o meio e o fim da graduação, e auxiliam no processo de compreensão da formação do estudante ao longo do curso. Conforme o currículo adotado pela instituição, do primeiro ao quinto semestre os estudantes cursam o ciclo básico, caracterizado por conter disciplinas estruturantes, como Anatomia Humana e Fisiologia e as primeiras inserções na Medicina Comunitária. Do sexto semestre em diante, os estudantes iniciam o contato com as especialidades médicas, aumentam a frequência de práticas hospitalares e ambulatoriais e o contato direto com médicos-especialistas. No nono semestre, inicia-se o internato médico, em que os estudantes recebem aprofundamento em quatro grandes áreas: Cirurgia Geral, Ginecologia, Pediatria e Clínica Médica, finalizam com a obtenção do título de médico, ao término da décima segunda fase (FUNDAÇÃO UNIVERSIDADE REGIONAL DE BLUMENAU, 2005).

A utilização dos dados obtidos por meio dos questionários foi condicionada à assinatura do termo de consentimento livre e esclarecido, pelos pesquisados. A pesquisa foi aprovada e liberada em 22 de junho de 2018, pelo Comitê de Ética da instituição, Universidade Regional de Blumenau- FURB, com o CAAE: 89188918.0.0000.5370.

\section{Análise dos dados}

Os dados socioeconômicos obtidos com o questionário foram analisados quantitativamente e comparados aos dados do Enade 2016. Em que pese a tendência positivista da pesquisa quantitativa, a utilização desta abordagem metodológica, quando associada à análise qualitativa, nos oferece uma possibilidade aprofundada de compreensão (Minayo e Sanches, 1993).

As mensagens do questionário foram analisadas por meio de análise de conteúdo. Para Franco (2005, p. 11), esta técnica é “usada para produzir inferências acerca de dados verbais e/ou simbólicos, mas, obtidos de perguntas e observações de interesse de um determinado pesquisador". A unidade de análise escolhida foi a análise temática. Fazer este tipo de análise em uma pesquisa qualitativa consiste em desvelar a presença, ou não, de determinado tema no processo de comunicação do pesquisado, e evidenciar, assim, a relação de significância com o objeto de estudo (Franco, 2005). O tema, conforme Bardin (2011, p. 131), “é uma unidade de significação que se liberta naturalmente de um texto analisado e que é, geralmente, utilizado como unidade de registro para estudar motivações de opiniões, atitudes e valores".

As motivações acerca da escolha pelo curso de medicina apresentadas pelos estudantes partem, conforme representadas (Figura 1), inicialmente, de um 
ideal de 'ajuda ao próximo' e caminham, paralelamente à evolução do Curso, para o ideal de 'retorno financeiro' e pela 'sensação de autossuficiência'. Estes três ideais foram identificados, por meio da análise de conteúdo (Franco, 2005), das respostas ao seguinte questionamento presente no questionário: Por que você escolheu cursar medicina?

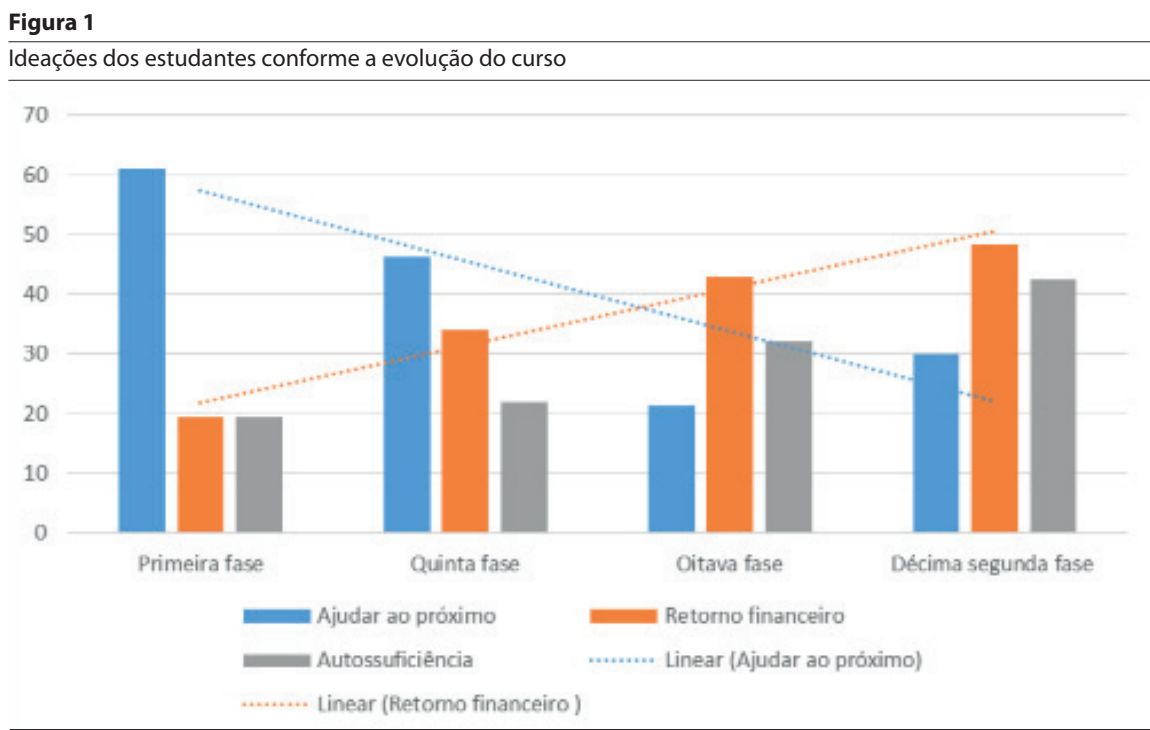

Fonte: As autoras.

As falas a seguir, excertos das respostas ao questionário, são exemplos da presença do ideal de 'ajudar o próximo', nos estudantes da primeira fase do curso:

Tenho o sonho de ajudar as pessoas e, apesar de isso ser possível em qualquer profissão, acredito que em medicina seja uma forma mais imediata e próxima ao paciente/pessoa, uma vez que sonho em trabalhar no Médicos Sem Fronteiras.

Busco na medicina uma forma de ajudar o maior número de pessoas carentes de cuidados médicos, assim como a realização profissional.

Eu escolhi cursar medicina porque acredito que por meio desse curso/profissão posso realizar ações e auxílio à comunidade local e global, priorizar o bem-estar físico e mental da pessoa. Além disso, optei por medicina também por ser uma profissão com muitos diferenciais em questão de formas de ajudar o ser humano, o que vai desde a trabalhar apenas em hospitais com ou sem remuneração, até fazer trabalhos humanitários...

Esta representação idealista apresentada pelos estudantes pode ser compreendida como aquilo que a sociedade idealiza, por meio da figura do mé- 
dico ideal, nestes estudantes recém-ingressos. Acerca deste fenômeno diz Arcoverde (2004, p. 72):

O aluno recém-admitido no curso de medicina possui uma representação leiga da profissão médica. Uma representação idealista, vaga e até mesmo abstrata, própria da fase adolescente por que estão passando. [...] estudantes secundaristas, no momento de optar pela carreira médica, apresentam uma concepção em que o salvar e o curar estão presentes sem uma noção real dos limites da profissão.

Como reforço à representação idealista do médico, há um conhecimento, ainda muito abstrato e superficial, das reais condições de trabalho dos profissionais da saúde, de forma geral, e das limitações da profissão médica. Estas representações tendem a ser reelaboradas ao longo da graduação, influenciadas pelas relações interpessoais e acadêmicas (Arcoverde, 2004).

O ideal de ajuda ao próximo apresenta-se de forma decrescente ao longo do curso, sendo substituído pela sensação de autossuficiência e pelo desejo de retorno financeiro. Porém, mostra pequeno aumento na transição da oitava para a décima segunda fase, fato associado, por nós autoras, à entrada destes estudantes no internato médico, o que intensifica o contato com os pacientes e com a prática médica. Carvalho, Garcia e Rocha (2006) confirmam que o contato com os pacientes, quando os estudantes apresentam maior autonomia na condução da relação, lhes confere maior interesse pela humanização da medicina. Ainda, segundo os autores, quanto mais precoce o contato entre pacientes e estudantes de medicina, maiores são as chances destes optarem por prestar serviços ligados ao Sistema Único de Saúde.

Com a evolução do curso, a ideação por nós denominada de autossuficiência, caracterizada pelo sentimento de empoderamento, aparece mais enfaticamente nas declarações dos estudantes. A escolha pela profissão que, inicialmente, baseava-se na ajuda ao próximo e no altruísmo é, gradativamente, substituída pela sensação de poder. Segundo Lampert (2009), a educação médica, pautada pela aquisição de habilidades técnicas, confere ao estudante esta sensação de autossuficiência.

Os trechos a seguir são respostas retiradas dos questionários dos estudantes da oitava e décima segunda fases e ratificam a ideação de autossuficiência:

Escolhi cursar Medicina porque eu tenho capacidade para isso.

Aptidão profissional.

Porque tenho capacidade para isso.

Porque eu sou capaz. 
Quando contrastadas com as respostas dos estudantes recém-ingressos, baseadas no altruísmo e repletas de justificativas, as respostas dos estudantes das fases finais apresentam-se mais objetivas e focadas no seu empoderamento como médicos em formação. Esta objetividade tem relação com a característica tecnicista da educação médica, a qual consta como um dos fatores para esta sensação de autossuficiência. Além disso, a evolução do curso oferece aos estudantes um intenso convívio com profissionais da medicina, diferentemente do que ocorre nas fases iniciais do curso, em que os docentes são, na sua maioria, de outras áreas da saúde (Lampert, 2009).

De maneira semelhante à ideação de autossuficiência, a ideação de retorno financeiro ganha destaque nas respostas dos estudantes das fases mais avançadas:

Entrar em contato com um meio intelectual pensante no qual poderia buscar conhecimento e achar respostas. Além de associar esse anseio pelo estudo com uma remuneração justa de acordo com meu esforço. E, claro, interesse na área de biologia, voltado para a saúde.

Capacidade de ajudar outras pessoas, realização profissional, retorno financeiro, estabilidade no futuro.

Remuneração, prestígio, facilidade e interesse pelo assunto.

Foi a opção que apresentava uma qualidade de vida e remuneração que era mais atraente.

O processo de transformação das ideações acerca do fazer médico não aparece como exclusividade desta instituição ou dos estudantes pesquisados. Sobre esta mudança acerca do fazer médico, afirma D’ Ávila (2003, p. 70): “Todo estudante de medicina é um idealista no início e um cínico no final". A gravidade desta afirmação é desdobrada por Beltrame (2006) em tese de doutorado, em um único questionamento: Seria o curso médico formador ou deformador? Baseada nesta pergunta, a autora se desafia a conhecer e a compreender quais forças atuariam neste fenômeno de transformação dos acadêmicos, levando-os a uma aparente perda da humanização. Ao fim da pesquisa, a autora aponta para o papel do docente, principal ator na formação médica, na contribuição para a perda dos sentimentos humanistas dos acadêmicos. Isso porque, em tese, o docente anularia a visão da medicina geral e humanista ao transferir aos estudantes a ideia do uso de equipamentos e de tecnologias para o tratamento e diagnóstico de patologias, num sistema de atendimento privado de alto nível e de prática neoliberal. Dessa forma, diminuiria, também, o interesse dos estudantes por carreiras com vínculos públicos. 
A transformação da percepção dos estudantes sobre os motivos de escolha do curso é clara. São três diferentes motivos - ajuda ao próximo, autossuficiência e retorno financeiro - que se apresentam comuns à maioria dos estudantes das turmas pesquisadas, e evidenciam um processo coletivo de transformação. Este processo de identificação coletiva é definido por Ciampa (2012, p. 64): “O conhecimento de si é dado pelo reconhecimento recíproco dos indivíduos identificados através de um determinado grupo social que existe objetivamente, com sua história, suas tradições, suas normas, seus interesses etc."

Apesar de estarem situadas em cenários e tempos muito diversos, os dados apresentados aqui muito se assemelham àqueles apresentados por Becker (1992) acerca da mudança na perspectiva de tornar-se médico em estudantes de medicina norte-americanos na década de 1960. Sobre o processo coletivo de mudanças, afirma o autor:

As dificuldades encontradas na graduação médica são tantas, e os estudantes se sentem tão pressionados por elas, que as experiências vividas em outras circunstâncias e instituições não são aplicáveis à graduação médica. Diante deste fato, as perspectivas de ação dos estudantes se tornam muito similares. (Becker, 1992, p. 211, tradução nossa)

Tais achados nos permitem inferir que as relações mantidas durante o curso de graduação em medicina, sejam elas intrínsecas ou não ao ambiente acadêmico, se apresentam como fatores da construção identitária do profissional médico em formação. Tal fato evidencia uma condição de 'fechamento' (Goffman, 2001), caracterizada pelo pertencimento a determinado grupo e, ao fazer parte dele, o sujeito se afasta, necessariamente, de pertencimentos a outros. A graduação médica atuaria, simbolicamente, como um grupo fechado, e os estudantes, ao passarem pelo processo da graduação, se identificariam, de maneira gradativa, às normas e costumes estabelecidos por este grupo.

A graduação médica, em seu fechamento institucional, configura aquilo que Lane (2012) chama de processo grupal. A autora evidencia que os grupos são uma forma de compreendermos como as ações sociais e coletivas atuam sobre um indivíduo, "partindo do pressuposto que toda ação transformadora da sociedade só pode ocorrer quando indivíduos se agrupam." (Lane, 2012, p. 78).

Submetidos à condição de fechamento, como consequência ao pertencimento a um grupo já histórico e socialmente definido, os estudantes de medicina apresentam-se como um grupo, ao longo da graduação, grosso modo, homogêneo. Deste modo, percebe-se a formação de identidades, sobretudo profissionais, muito semelhantes, construídas por relações sociais, dentro e fora do ambiente acadêmico, regidas por normas e interesses. 
É, portanto, nas relações construídas ao longo do curso, que o estudante de medicina tem sua identidade socioprofissional moldada. Este movimento, que surge da necessidade de adaptação a determinadas realidades, permite ao estudante assumir um papel facilmente identificado, em que suas atitudes são reconhecidas pelos demais como uma justificativa para agir da forma que age (Becker, 1992).

\section{Considerações finais}

Partimos da ideia de que os estudantes, apesar de serem sujeitos diversos e apresentarem-se como sujeitos sociais, com histórias de vida ímpares, transformavam-se, ao longo da graduação, em sujeitos muito semelhantes, com relação às práticas médica e social. Apresentariam, por exemplo, os mesmos anseios profissionais e pessoais, atitudes e práticas muito semelhantes. As motivações pela escolha da profissão também se mostram bastante similares, variam entre ajuda ao próximo, capacidade pessoal e retorno financeiro.

A ajuda ao próximo apareceu sendo substituída, gradualmente, pelo retorno financeiro, conforme a evolução do curso, em grande parte dos estudantes pesquisados. Essa mudança acerca da motivação pela escolha do curso está, para este estudo, sustentada em duas principais razões: a inserção do estudante no submundo institucional da medicina e o papel socialmente definido do 'estudante de medicina ideal'.

Submundos institucionais são, para Berger e Luckmann (1976), caracterizados como espaços de legitimação da distribuição social do conhecimento, organizados em instituições que fortalecem a divisão do trabalho e que dão origem às especificidades das classes profissionais. O curso de medicina, nesta pesquisa, aparece como legitimador de um conhecimento específico e com poder de diferenciação social. Neste sentido, podemos afirmar que a socialização secundária (Berger e Luckmann, 1976) tem papel fundamental na formação identitária do estudante de medicina.

É neste processo de identificação com o meio em que se encontra inserido que o estudante desenvolve, ao longo dos seis anos de graduação, competências técnicas e, principalmente, a sensibilidade e a capacidade de empatia. Tal constatação nos leva a afirmar que o ambiente acadêmico competitivo e a supervalorização do ensino por especialidades contribuem, de forma importante, para a mudança na perspectiva da profissão, que se inicia baseada na ajuda ao próximo e termina na busca pelo retorno financeiro.

Diferentes histórias de vida e experiências e, consequentemente, diversas vivências, nos mostraram sujeitos socioculturalmente distintos, porém envoltos por ritos e estereótipos comuns, socialmente convencionados. Fugir deste padrão parece ser muito mais uma questão de tomar consciência daquilo que os cerca do que uma escolha. 


\section{Colaboradores}

Clarisse Daminelli Borges Machado participou da concepção do estudo, realizou pesquisa de campo, geração e análise dos dados, redação da primeira versão do manuscrito e aprovação da versão final. Andrea Soares Wuo participou da concepção e orientação do estudo, análise dos dados, revisão da redação do manuscrito e aprovação da versão final.

\section{Financiamento}

Esta pesquisa não recebeu quaisquer tipos de financiamento.

\section{PROCESO DE SOCIALIZACIÓN EN LA FORMACIÓN DE LA IDENTIDAD DEL ESTUDIANTE DE MEDICINA}

Resumen Este artículo se planteó como objetivo evidenciar y analizar los cambios relacionados a las expectativas de convertirse en médico a lo largo de la carrera de medicina. El estudio, realizado entre abril y junio del 2018, incluyó a estudiantes de medicina de una institución pública de Enseñanza Superior del Estado de Santa Catarina, Brasil, matriculados respectivamente en los períodos primero, quinto, octavo y duodécimo. Después de aplicar el cuestionario se analizaron 145 respuestas a la siguiente pregunta: ¿Por qué usted eligió cursar medicina? Los datos analizados por medio del análisis de contenido mostraron un aumento a lo largo de la carrera por lo que se conoce como 'retorno de la inversión' y una disminución del interés en 'ayudar al prójimo'. Los resultados, analizados con base en teorías que abordan los procesos de socialización y de formación de la identidad, mostraron que a pesar de estar inmersos en diferentes realidades socioculturales, los individuos se encuentran rodeados por rituales y estereotipos comunes, aceptados socialmente por las normas sociales y construidos históricamente por el proceso de constitución de la identidad médica.

Palabras clave educación médica; socialización; formación de la identidad; identidad profesional.

\section{Nota}

${ }^{1}$ Este artigo é resultado de dissertação de mestrado de Clarisse Daminelli Borges Machado, área de Educação, intitulada "Movimento e Processo: a formação identitária do estudante de medicina", apresentada ao Programa de Pós-Graduação em Educação da Universidade Regional de Blumenau- FURB, em 2018. Não há conflitos de interesse. 


\section{Referências}

ARCOVERDE, Tarcísio L. Formação médica: (des)construção do sentido da profissão - a trajetória da representação social. 2004. 128 f. Dissertação (Mestrado em Educação) - Universidade Regional de Blumenau, Blumenau, 2004.

BARDIN, Laurence. Análise de Conteúdo. 1. ed. São Paulo: Edições 70, 2011.

BECKER, Robert S. Boys in white: student culture in Medical School. 4. ed. London: Transaction Publishers, 1992.

BELTRAME, Registila L. A formação do Médico: um debate à luz das Diretrizes Curriculares Nacionais. 2006. 228 f. Tese (Doutorado em Educação) - Pontifícia Universidade Católica de São Paulo, São Paulo, 2006.

BERGER, Peter L.; LUCKMANN, Thomas. A construção social da realidade: tratado de sociologia do conhecimento. . 3. ed. Petrópolis: Vozes, 1976.

BRASIL. Ministério da Educação. Questionário socioeconômico do Exame Nacional de Desempenho do Estudante, 2016. Disponível em: $<$ http://portal.inep.gov.br/conceito-enade>. Acesso em: 24 jun. 2017.

CARVALHO, Sérgio R.; GARCIA, Rosana A.; ROCHA, Daniel C. O ensino da Saúde Coletiva no curso médico da Unicamp: experiências inovadoras junto a unidades básicas de saúde. Interface: Comunicação, Saúde, Educação, Campinas, v. 10, n. 20, p. 457-472, jul.- dez. 2006. Disponível em: <www.scielo.br/scielo. php?pid=S1414-32832006000200013\&script=sci... tlng...>. Acesso em: 19 jul. 2018.

CIAMPA, Antônio C. A estória do Severino e a história da Severina: um ensaio de psicologia social. 6. ed. São Paulo: Brasiliense, 1998.

CIAMPA, Antônio C. Identidade. In: LANE, Sílvia T. M.; CODO, Wanderley (Orgs.). Psicologia Social: o homem em movimento. 14. ed. São Paulo: Brasiliense, 2012. p. 58-75.
COSTA, Maria C. Sociologia: introdução à ciência da sociedade. 2. ed. São Paulo: Moderna, 2000.

D'ÁVILA, Roberto. O Conselho Federal de Medicina e o ensino da Ética e da Bioética. Bioética. v.11, n. 2. 2003.

DUBAR, Claude. A crise das identidades: a interpretação de uma mutação. 3. ed. São Paulo: Edusp, 2009.

DUBAR, Claude. A socialização: construção das identidades sociais e profissionais. Tradução: Andréa Stahel Monteiro da Silva. 1. ed. São Paulo: Martins Fontes, 2005.

DURKHEIN, Émile. O que é Fato Social. In: DURKHEIN, Émile. As regras do método sociológico. Tradução: Maria Isaura Pereira de Queiroz. 6. ed. São Paulo: Nacional, 1972.

FRANCO, Maria L. P. B. Análise de conteúdo. 2. ed. Brasília: Liber Livro Editora, 2005.

FUNDAÇÃO UNIVERSIDADE REGIONAL DE BLUMENAU. Projeto político-pedagógico do curso de Medicina, 2005. Disponível em: $<$ http://www.furb.br/web/upl/graduacao/projeto_pedagogico/201703171434230.PPC\%20 MEDICINA \%202015.pdf >. Acesso em: 4 jun. 2017.

GOFFMAN, Erving. A representação do eu na vida cotidiana. 1. ed. Petrópolis: Vozes, 2001. 233 p.

HELLER, Agnes. O cotidiano e a história. Tradução: Carlos Nelson Coutinho e Leandro Konder. 4. ed. Rio de Janeiro: Paz e Terra, 1992.

HUGHES, Everett C. Men and their work. 1. ed. London: The Free Press, 1958.

LAMPERT, Jadete B. Tendências de mudanças na Educação Médica do Brasil: tipologia das escolas. 2. ed. São Paulo: Hucitec, 2009.

LANE, Sílvia T. M. O processo grupal. In: LANE, Sílvia T. M.; CODO, Wanderley (Org.). 
Psicologia Social: o homem em movimento. 14. ed. São Paulo: Brasiliense, 2012. p. 78-98.

MINAYO, Maria C. S.; SANCHES, Odécio. Quantitativo-Qualitativo: oposição ou complementaridade? Cadernos de Saúde Pública, Rio de Janeiro, v. 9 n. 3, p. 239-262, jul.- set., 1993. Disponível em: <https://www.scielosp. org/pdf/csp/1993.v9n3/237-248/pt>. Acesso em: 10 out. 2018.

RIOS, Izabel C. Subjetividade contemporânea na educação médica: a formação humanística em medicina. 2010. 328 f. Tese (Doutorado em Ciências) - Faculdade de Medicina, Universidade de São Paulo, São Paulo, 2010.
SANT'ANA, Ruth B. A dimensão social na formação do sujeito na Psicologia. Memorandum, Belo Horizonte, v. 12, p. 125-142, abr. 2007. Disponível em: <http://www.fafich. ufmg.br/ memorandum/a12/santana01.pdf $>$. Acesso em: 06 fev. 2018.

SANTOS, Valéria O. A longa espera: a entrada tardia de estudantes das classes médias no curso de Medicina da UFSJ. 2012. 228 f. Dissertação (Mestrado em Educação) - Universidade Federal de São João del-Rei, Minas Gerais, 2012.

WEBER, Max. Conceitos básicos de sociologia. 5. ed. São Paulo: Centauro, 2002. 